\title{
Investing in Water Purification Infrastructure in an Emerging Market: Some Considerations for Impact Investors in South Africa
}

\author{
Stephen McCallum ${ }^{1}$, Suzette Viviers ${ }^{1}$ and Rafael Robina Ramírez ${ }^{2}$
}

\begin{abstract}
This study investigated the role that impact investors could play in the water purification infrastructure sector. Impact investors are individuals and institutions that invest in companies, organisations and funds with the aim of generating social and environmental impact alongside financial return. These investors are increasingly interested in emerging markets such as South Africa. As scholars have raised concerns about investors and companies profiting from the provision of a basic human right, the views of 20 experts were also gauged on this topic. Semi-structured personal interviews were conducted with key role players in the South African impact investment value chain (mostly investors) and the water provision system. Interviewees saw an important role for private sector investment in water purification infrastructure given government's inability to meet the growing demand for potable water. Participants were, however, wary of private-publicpartnerships and felt that investors and companies will only face a moral dilemma if they overcharge consumers for purified water. Impact investors should give careful consideration to domestic water users' ability to pay as well as their needs and expectations. The development of a blended financing model is proposed.
\end{abstract}

Keywords: Impact investing; emerging market; water purification infrastructure; South Africa; basic buman rights; ethical concerns

\section{Introduction and Background to the Study}

In the time it takes one to read the next two pages over 50 people globally would have died from diseases linked to unsafe drinking water (Gleick, 2002). The disease burden caused by insufficient water and sanitation infrastructure is estimated to result in approximately five million deaths per year globally. Of this group, two million mortalities occur from water-related diarrhoea alone (Montgomery \& Elimelech, 2007; Prüss, Kay, Fewtrell \& Bartram, 2002).

As elsewhere in the developing world, many South Africans do not have 'acceptable access' to potable water (Statistics South Africa, 2016). 'Acceptable access' can be measured in terms of distance, availability and quality. According to the World Health Organization (WHO), a water source should be located within one kilometre of the user's place of residence and should provide a minimum of 20 litres per person per day (Zolnikov \& Salafia, 2016). The WHO (2011) also provides detailed guidelines on what could be considered safe drinking water. In South Africa, water that complies with the South African National Standard 241 Drinking Water Specification is defined as potable water. Hodgson and Manus (2006) claim that water of this standard does not pose a significant risk to health over a lifetime of consumption, nor to babies, the immunocompromised or the elderly. Since September 2000, the South African government has 
provided a minimum of 25 litres per person per day or six kilolitres per household per month gratis. They define a household as "everyone living on one stand" (DWAF, 2004). In 2017/18, some regions in the Western, Northern and Eastern Cape provinces of the country experienced the worst drought on record. Some experts even claim that Cape Town could become the first major city in the world to run out of water in the near future (Welch, 2018). Water shortages in South Africa are likely to get worse as the population continues to grow and as the impact of climate change intensifies.

The United Nations Human Rights Council Resolution 27/7 of September 2014 entitles every human, without discrimination, to have "access to sufficient, safe, acceptable, physically accessible and affordable water for personal and domestic use and to have physical and affordable access to sanitation, in all spheres of life, that is safe, hygienic, secure, socially and culturally acceptable and that provides privacy and ensures dignity". The primary responsibility for fulfilling this basic human right lies with a country's government (Connor, 2015). The South African Department of Water and Sanitation (DWS) is regarded as the custodian of the country's water resources. As such, the DWS oversees the entire water provision process. Some of the DWS' functions (such as water purification) are constitutionally assigned to sector partners such as water boards and municipalities. This government department has to ensure that all South Africans have access to dignified sanitation and potable water (DWS, 2016). To achieve these goals, the DWS formulates and oversees the implementation of water policies through the country's nine provincial offices.

Governments across the globe are faced with providing water infrastructure and services beyond what their budgets can support (Drexler et al., 2014; Rodriguez et al., 2012). As elsewhere in the developing world, the South African government has not been able meet the increasing demand for potable water (DWS, 2014; Cheung, 2010; Montgomery \& Elimelech, 2007). In his 2016 national budget speech, the Minister of Finance allocated ZAR15 billion over the medium term towards the construction of bulk water and sanitation infrastructure (Gordhan, 2016). A further ZAR502 million was reprioritised to increase access to water in drought-stricken areas. According to Turton (2016), government's response was too late and inadequate given the severity of the drought in many parts of the country.

A major concern is that the South African government does not have the required institutional or financial capacity to implement its infrastructure investment plans as set out in the National Water Resource Strategy (Lubisi, 2014) due to, amongst others, poor co-ordination between departments, a lack of skills and insufficient funding (Orr et al., 2009). Given the large and growing public funding gap (DWS, 2018, Millson \& Roux, 2015; DWA, 2013) private sector involvement in the South African water sector has thus become vital (Ruiters \& Matji, 2016).

Private sector could get involved in the provision of potable water through publicprivate-partnerships (PPPs). Research shows that governments in developed countries often enter into PPPs to develop new water infrastructure in the face of budgetary constraints (Trebilcock \& Rosenstock, 2015). These partnerships typically involve "transferring some or all of the 'assets' [and]/or 'operations' of [the] public water systems into private hands” (Ameyaw \& Chan, 2015).

Proponents of private sector involvement argue that it could enhance efficiency, extend 
public service delivery (particularly to rural and peri-urban areas), expand and improve water infrastructure and relieve stress on fiscal budgets (Brinkerhoff \& Brinkerhoff, 2011; Koppenjan \& Enserink, 2009; Kirkpatrick et al., 2006). Others advocated claim that private sector providers could offer water that is of a better quality than that provided by governments (Cobbing et al. 2015; Momba et al., 2006). Proponents in South Africa posit that water treated by the DWS still contains chemicals which are harmful in the long term, whereas water provided by private vendors is safe to consume (ibid). Innovation through private sector research and development could also drive down costs (Slaughter, 2010).

The primary argument against private sector involvement centre on the transfer of control of an essential service from government to profit-driven entities (Davis, 2005; Lee \& Floris, 2003). Koppenjan and Enserink (2009) raise concerns about the compatibility of these entities' short-term focus on financial returns and the long-term approach needed to meet sustainability targets. Other apprehensions, which all have ethical implications, include the risk of monopolistic service provision, the exploitation and misallocation of resources, the production of social and environmental externalities, regulatory weaknesses and the under-provision of basic needs (Venkatachalam, 2015; Koppenjan \& Enserink, 2009; Kirkpatrick et al., 2006). Experience shows that selling water on the open market does not address the needs of poor citizens. Murthy (2013) explain that domestic users who do not have acceptable access to potable water must buy water from local shops or private vendors. As these suppliers generally purchase water in bulk they can charge premium prices.

\section{Problem Investigated}

Maharaj (2003) found that there was minimal public support for the privatisation of water and sanitation services in South African in any shape or form. The private sector's hesitation to engage in PPPs might be rooted in their fear of political interference and concerns about corruption and bribery (Van den Brink, 2011). In light of the apprehensions surrounding PPPs, the authors set out to investigate the role that private sector impact investors could play in the local water sector. Impact investors are individuals and institutions that invest in companies, organisations and funds with the aim of generating social and environmental impact alongside financial return (GIIN, 2018; Saltuk, 2012). In this paper social impact was seen to encapsulate the notions of human dignity and equality.

An impact investor in the water sector could, for example invest in private companies that build purification infrastructure (e.g. desalination plants), companies that manufacture and/or sell water purification products (e.g. filters) or companies that sell potable water (e.g. bottled spring water). These private companies typically focus on providing access to drinking water in areas where there is poor, little or no access to potable water. Impact investing is a responsible investment that is gaining substantial traction globally (Mudaliar et al., 2016a; Combs, 2014). The impact investment market in South Africa is the largest in Sub-Saharan Africa and is showing steady growth (Sales, 2015).

As scholars have raised concerns about investors and companies profiting from the 
provision of a basic human right (Koppenjan \& Enserink; 2009; Davis, 2005; Lee \& Floris, 2003), the authors also investigated this topic. Local critics' unease not only stems from the high level of poverty in South Africa, but also from the widening income gap between communities. According to Statistics South Africa's (2017) latest "Poverty trends in South Africa" survey, the percentage of "poor" citizens living in the country has risen sharply from 2011 to 2015 . More than half of the population $(55.5 \%)$ was considered poor in 2015 (using the upper-bound poverty line of R992 per person per month).

In light of these statistics, a moral quandary clearly emerges in disadvantages communities. As shown in a study among impoverished South Africans, human dignity and equality are often disregarded when providing water to these individuals (Robina Ramírez \& Sañudo-Fontaneda, 2018). Government's failure to meet citizen's basic water and sanitation need not only compromises their health, but also results in lost education hours, limited food production, stunted economic development and civil unrest (Morudu, 2017; Sivakumar, 2011). All of these adverse outcomes deeply affect the physical and emotional well-being of a country's citizens.

\section{Methodology}

Given the exploratory nature of the study, a qualitative research paradigm was deemed appropriate. Secondary data were collected through a review of academic journal articles, industry reports and books. Primary qualitative data were sourced from experts in the local impact investment market and the water provision process. At the time of conducting the primary research, no usable population or sample frame existed outlining the role players in the local impact investment market. A sample frame thus had to be compiled from sources such as Mudaliar et al. (2016b), Rockey (2016) and Sales (2015). A second sample frame was assembled from individuals and entities that were identified as experts in the research and development of water purification infrastructure and that were listed in the South African water directory (Water directory, 2017).

Judgemental and snowball sampling techniques were used to identify eligible participants. The sample consisted of eight impact investors, some of whom were employed at large asset managers and others at small boutique investment houses. In addition five role players in the impact investment market were included as well as seven experts in the water provision process. The latter group consisted of academics, researchers and consultants. To qualify for inclusion, a participant had to be an executive decision maker or person in a managerial role who has made or has helped facilitate one or more impact investments over the period 2011 to 2016. Similarly, role players in the water provision process were identified based on their expertise in different water purification processes and their involvement with the research and development of water purification infrastructure. These individuals were either an executive decision-maker or a person in a managerial role who has had experience in the water provision process over the past five years.

The sample consisted of an equal number of men and women. The average age (30 to 39) shows that a mature group of individuals participated in this study. They were also experienced as demonstrated by the average number of years work experience (11 to 15 
years). The senior positions that were held by the participants at the time of the study provide further evidence that authoritative opinions were gathered. Of the twenty participants, four were CEOs, five were heads of departments, six were managers and the remaining five were consultants and analysts. In addition, thirteen of the participants had masters' or doctoral degrees.

An interview guide was developed to facilitate semi-structured personal interviews. Ethical clearance was obtained in April 2017 and the interviews were conducted in May and July 2017. All interviews were audio-recorded and professionally transcribed. Directed content analysis was then used to make sense of the raw qualitative data. Credibility was ensured by gauging the views of experts in the local impact investment market, audio-recording the interviews, taking meticulous notes and triangulating thoughts and ideas. To achieve dependability, a reflective appraisal was conducted to confirm that the findings reflected the essence of the raw data gathered. Steps were also taken to ensure that the focus remained on the opinions of the participants and not on those of the authors.

\section{Results and Discussion}

Interviewees were firstly asked to comment on the role that the impact investors could play in the water purification process. In line with Connor (2015), most participants were of the opinion that the South African government should be primarily responsible for financing and facilitating water provision. However, all of the experts felt strongly that there should be some sort of involvement from the private sector. Interviewee Three captured the general sentiment by saying that "there is an express[ed] requirement for government to be the steward of the natural resources around water, but I think from a hard infrastructure perspective there's definitely scope for private sector participation".

Participants cited the lack of financial capacity, the country's small tax base and the limited municipal capability as reasons for the government's inability to fulfil their waterrelated responsibilities towards citizens. A number of interviewees suggested that government should, given the lack of capacity and financial resources, outsource at least some of their responsibilities. Smaller scale water provision projects could thus be outsourced or structured through PPPs.

Although participants acknowledged the need for (more) private sector involvement in water purification, they were also aware of the risks of privatisation. In line with Maharja (2003), some of the highlighted risks include the extremely detrimental effects on the country's indigents due to the commercialisation of potable water. In the interviewees' opinion, indigents do not have the ability to pay for basic services. Therefore, their access could be substantially limited if the provision of water was privatised.

Participants recognised several opportunities to generate financial returns in the local water sector. The first and most regularly mentioned opportunity was to invest in waste water treatment systems. The general opinion was that there are many technological advancements in this area of the water provision process. Likewise, the consensus was that the market for treating grey water and discharging it back into the water system is growing. These types of infrastructure not only generate financial returns, but often deal 
with sanitation and clean water problems concurrently.

Very few interviewees thought that innovation in desalination would drive down costs. In fact, many believed that desalination would increase water purification costs if implemented today. The main concern was that the energy consumption required to desalinate seawater is extremely expensive. Therefore, they saw opportunities in developing energy saving solutions for the desalination process such as solar energy. Other forms of innovative technologies were considered to be better options to drive down costs, including "financial models" that could be designed and implemented to fund water purification infrastructure. One such solution that was suggested was to give a 100 per cent assurance of water supply to industries that are heavily dependent on water such as mining and healthcare.

Another identified opportunity was the treatment of acid mine drainage (the outflow of acidic water from a mine). According to Participant Eighteen, mines are high-use consumers of water and the polluted water should be regarded as a liability. Furthermore, the communities surrounding the mines often do not have acceptable access to potable water. Therefore, treating water that is polluted by mining activities and reselling the purified water to surrounding communities could be another investment opportunity. Considering the adverse consequences of acid mine drainage (McCarthy, 2011; Naicker, Cukrowska \& McCarthy, 2003), investments in innovative infrastructure targeting this polluted water should create easily measurable environmental and social impact.

Participants were furthermore asked to comment on whether it is morally acceptable to profit from providing a basic human right. Seventeen of the 20 participants said that there is nothing wrong with doing so in a capitalist country. The other three did not answer the question. Those who responded, however, specified that potable water should be charged at a "reasonable" price. Participants qualified their view by stating that financial return cannot be at the expense of those struggling to access potable water. In other words, "individuals should not be denied access to potable water if they cannot afford it." The general view was that the levels of return that is pursued cannot be to the detriment of those paying for the basic need.

Most of the interviewees were also of the opinion that if investments were made to provide acceptable access to potable water, the water should be affordable even for the poorest of the poor. Furthermore, they felt that access should be available to the poorest of the poor from the outset. Participant Twenty highlighted that it would be very difficult to cross-subsidise or structure deals that the poorest of the poor in a community pay reduced rates unless good metrics were implemented. Therefore, acceptable access to potable water should be affordable for as many people as possible. Many participants, however, mentioned that the poorest of the poor are actually provided for by the government's free basic allotment of water.

Participant Sixteen also emphasised that the 'poorest of the poor' is a relative term. The government has established a definition of poverty below a certain income level. However, this participant was of the opinion that if an individual lives in an informal community and has some sort of roof over their head, they should not be considered as the 'poorest of the poor'. He stated:

"someone who has no place to stay and who owns absolutely nothing should qualify as 
the 'poorest of the poor'. It would be unethical to charge the second individual for potable water, but most of the population can afford to pay for potable water and the investment should thus be made".

Some interviewees also acknowledged that the provision of potable water is more sensitive than that of other basic human rights. For example, electricity supply can be cut off if the consumer fails to pay for it because there are alternative options. Acceptable access to potable water, however, cannot be refused by a provider as it is essential to everyday life. Therefore, "acceptable access to water will always be regulated and complicated". Participant Sixteen claimed that the South African government has created an unrealistic expectation among citizens that all water should be free of charge. This investor argued that a household could live on "far less than that [the government's gratis provision of six kilolitres per household per month]".

\section{Conclusions and Implications}

Participants were very clear that the primary responsibility for providing potable water in South Africa lies with government. They do, however, see an important role for private sector investors to get involved given government's inability to meet the growing demand. Participants highlighted several risks associated with privatization. They mentioned that smaller scale projects could be outsourced or structured through PPPs. Most were of the opinion that consumers have to pay for the water that they consume. Determining a 'reasonable' price is, however, quite complex, especially as many South Africans expect water to be provided free of charge. Experts felt that investors and private companies will only face a moral dilemma if they overcharge consumers for purified water. They hence recognised the importance of respecting the dignity and rights all citizens.

More than half of the South African population can be classified as "poor". The government already caters for these individuals by providing a free allotment of six kilolitres per household per month. Impact investors who wish to get involved in the provision of potable water need to apply their minds when it comes to setting affordable prices. They need to acknowledge domestic users' ability to pay along with their expectations and needs. They should also test their assumptions about these pricing variables in practice and might have to consider a tiered pricing system for different market segments.

The authors are of the opinion that private sector investors' return expectations are unlikely to be met without substantial government subsidisation. As such, closer cooperation between impact investors, the DWS, water boards, municipalities and other key institutions in the water provision process is recommended. A blended financing model could be used to attract capital at various levels of risk. Government could provide grants that would act as first-loss capital to remove barriers and catalyse public or private investments. Special purpose vehicles could be created with various tranches into which mainstream investors (senior tranche), opportunistic investors (mezzanine tranche) and impact investors (junior tranche) can allocate capital. Such instruments could be used to channel capital towards water infrastructure through water boards without relaying that much risk to the mainstream investors. 
This study shows that there is scope for private sector investors in the water provision process in South Africa, especially in terms of water purification. It also illustrates that it is very difficult to determine an 'affordable' price for purified water. The complexity of this topic centres on achieving a balance between financial return and affordability. Consequently, the pricing of water needs to be high enough so that financial return prospects are attractive for investors and low enough to be affordable so that the consumers are not exploited. As described by Murthy (2013), entities can charge for water to recover their costs, but individuals and households cannot be denied acceptable access due to their inability to pay. It is therefore concluded that the balance between financial return and affordability needs to be carefully contemplated

The South African government should continue providing some water free of charge, but they should do a better job of managing domestic users' expectations. They should also do more to educate citizens on how to conserve this precious natural resource. Citizens should furthermore be educated about the cost of providing potable water and the need to conserve it. Organisations like the World Wildlife Fund could play a valuable role in this education. Similarly, educators could expose more commerce student to impact investing as a viable responsible investment strategy. More emphasis should be placed on the Sustainable Development Goals, specifically Number Six which deals with clean water and sanitation.

One limitation of the study is that most of the participants lived and worked in the Western Cape province of South Africa when the research was undertaken. Their views might have been influenced by the drought conditions that prevailed at the time. Future researchers could investigate the true value of water in South Africa in more detail across different provinces. They could, for example, engage with consumers in different Living Standards Measures (LSM) groups to understand their water expectations and needs.

\section{Acknowledgments}

The Harry Crossley Foundation is thanked for providing financial support.

\section{References}

Ameyaw, E.E. \& Chan, A.P.C. (2015). Risk ranking and analysis in PPP water supply infrastructure projects: An international survey of industry experts. Journal of Facilities, 8(7), 428-453.

Brinkerhoff, DW \& Brinkerhoff, JM, 2011. Public-private partnerships: Perspectives on purposes, publicness, and good governance. Journal of Public Administration and Development, 31(2), 2-14.

Cheung, P. (2010). The world's women: Trends and statistics 2010. United Nations. Retrieved from http://unstats.un.org/unsd/demographic/products/Worldswomen/WW_full report_color.pdf

Cobbing, J.E., Eales, K., Gibson, J., Lenkoe, K. \& Cobbing, B.L. (2015). Operation and maintenance and the perceived unreliability of domestic groundwater supplies in South Africa. South African Journal of Geology, 118(1), 17-32.

Combs, K. (2014). More than just a trend: the importance of impact investing. Corporate Finance Review, 18(5), 12-18.

Connor, R. (2015). Water for a sustainable world. UNESCO. Retrieved from http://www.unesco.org/new/en/natural-sciences/environment/water/wwap/wwdr/2015-waterfor-a-sustainable-world/

Davis, J. (2005). Private-sector participation in the water and sanitation sector. Annual Revien of Environment \& Resources, 30(1), 145-183. 
Drexler, M., Noble, A., Classon, E. \& Mercep, E. (2014). Charting the course: how mainstream investors can design visionary pragmatic impact investing strategies. World Economic Forum. Retrieved from http://www3.weforum.org/docs/WEF_ImpactInvesting_Report_ChartingTheCourse.pdf

DWA (Department of Water Affairs). (2013). National water resource strategy: Water for an equitable and sustainable future. Retrieved from https://www.dwa.gov.za/nwrs/LinkClick.aspx?fileticket=CIwWyptzLRk\%3D\&tabid=91\&mid=4 96

DWAF (Department of Water Affairs and Forestry). (2004). A history of the first decade of Water Service delivery in South Africa 1994 to 2004 - meeting the millennium development goals. Retrieved from http://www.dwa.gov.za/documents/publications/ firstdecade.pdf

DWS (Department of Water and Sanitation). (2016). About us. Retrieved from https://www.dwa.gov.za/about.aspx\#vision

DWS (Department of Water and Sanitation). (2014). Blue Drop Report. Retrieved from http://www.dwa.gov.za/Documents/Blue\%20Drop\%20Report\%202014.pdf

Gleick, P.H. (2002). Dirty water: Estimated deaths from water-related diseases 2000-2020. Pacific Institute. Retrieved from http://www.pacinst.org/wpcontent/uploads/sites/21/2013/02/water_related_deaths_report3.pdf

GIIN (Global Impact Investing Network). (2018). Annual Impact Investor Survey. $8^{\text {th }}$ Edition. Retrieved from https://thegiin.org/assets/2018_GIIN_Annual_Impact_Investor_Survey_webfile.pdf

Gordhan, P. (2016). Budget speech 2016. National Treasury. Retrieved from http://www.treasury.gov.za/documents/national budget/2016/speech/speech.pdf

Hodgson, K. \& Manus, L. (2006). A drinking water quality framework for South Africa. Water SA, 32(5), 673-678.

Kirkpatrick, C., Parker, D. \& Zhang, Y.F. (2006). An empirical analysis of state and private-sector provision of water services in Africa. World Bank Economic Review, 20(1), 143-163.

Koppenjan, J.F.M. \& Enserink, B. (2009). Public-private partnerships in urban infrastructures: Reconciling private sector participation and sustainability. Public Administration Review, 69(2), 284-296.

Lee, T. \& Floris, V. (2003). Universal access to water and sanitation: Why the private sector must participate. Natural Resources Forum, 27(4), 279-290.

Lubisi, C. (2014). Twenty year review: South Africa. The Presidency of South Africa. Retrieved from http://www.poa.gov.za/news/Pages/Twenty\%20Year\%20Review\%20South\%20Africa\%201994 $\% 20$ to\%202014.aspx Department planning, monitoring and administration.

Maharaj, A. (2003). Sustainable private sector participation in water supply and sanitation: An investigation of the South African experience with international comparative case studies. Unpublished doctoral dissertation. Durban: University of Natal.

McCarthy, T.S. (2011). The impact of acid mine drainage in South Africa. South African Journal of Science, 107(5/6), 1-7.

Millson, C. \& Roux, A. (2015). Water market intelligence report. Green Cape. Retrieved from http://greencape.co.za/assets/Uploads/GreenCape-Market-Intelligence-Reports-Water.pdf

Momba, M., Tyafa, Z. \& Makala, N. (2006). Safe drinking water still a dream in rural areas of South Africa. Case study: The Eastern Cape Province. Water SA, 32(5), 715-720.

Montgomery, M.A. \& Elimelech, M. (2007). Water and sanitation in developing countries: Including health in the equation. Journal of Environmental Science \& Technology, 41(1), 17-24.

Morudu, H.D. (2017). Service delivery protests in South African municipalities: An exploration using principal component regression and 2013 data. Cogent Social Sciences, 3, 1-15.

Mudaliar, A., Moynihan, K., Bass, R., Roberts, A. \& DeMarsh, N. (2016a). The landscape for impact investing in Southern Africa. The Global Impact Investing Network, February. Retrieved from https://thegiin.org/assets/documents/pub/Southern\%20Africa/GIIN_SouthernAfrica.pdf

Mudaliar, A., Pineiro, A. \& Bass, R. (2016b). Impact investing trends: Evidence of a growing industry. The Global Impact Investing Network, December. Retrieved from https://thegiin.org/assets/GIIN_Impact InvestingTrends Report.pdf

Murthy, S.L. (2013). The human right(s) to water and sanitation: History, meaning, and the controversy over privatization. Berkley Journal of International Law, 31(1), 89-149.

Naicker, K., Cukrowska, E. \& McCarthy, E.S. (2003). Acid mine drainage arising from gold mining activity in Johannesburg, South Africa and environs. Environmental Pollution, 122(1), 29-40. 
Orr, S., Cartwright, A. \& Tickner, D. (2009). Understanding water risks: A primer on the consequences of water scarcity for government and business. WWF. Retrieved from http://awsassets.panda.org/downloads/understanding_water_risk_iv.pdf

Prüss, A., Kay, D., Fewtrell, L. \& Bartram, J. (2002). Estimating the burden of disease from water, sanitation, and hygiene at a global level. Journal of Environmental Health Perspectives, 110(5), 537-542.

Robina Ramírez, R. \& Sañudo-Fontaneda, L.A. (2018). Human aspects of water management at impoverished settlements. The case of Doornkop, Soweto. Water, 10(330), 1-18.

$\backslash$ Rockey, N. (2016). Impact investing in South Africa: What the future holds. Trialogue, 29 July. Retrieved from http://trialogue.co.za/impact-investing-south-africa-future-holds/

Rodriguez, D.J., Van den Berg, C. \& McMahon, A. (2012). Investing in water infrastructure: Capital, operations and maintenance. Working Paper. Washington DC: The World Bank.

Ruiters, C. \& Matji, M.P. (2016). Public-private partnership conceptual framework and models for the funding and financing of water services infrastructure in municipalities from selected provinces in South Africa. Water SA, 42(2), 291-305.

Sales, T. (2015). Impact investment in Africa: Trends, constraints and opportunities. United Nation Development Programme, November. Retrieved from http://www.africa.undp.org/content/rba/en/home/about-us/AFIM/impact-investment-inafrica--trends--constraints-and-opportuniti.html

Saltuk, Y. (2012). A portfolio approach to impact investment. JP Morgan. Retrieved from https://www.jpmorganchase.com/corporate/socialfinance/document/121001_A_Portfolio_App roach_to_Impact_Investment.pdf

Sivakumar, B. (2011). Water crisis: From conflict to cooperation - An overview. Hydrological Sciences Journal, 56(4), 531-552.

Slaughter, S. (2010). Improving the sustainability of water treatment systems: Opportunities for innovation. The Solutions Journal, 1(3), 42-49.

Statistics South Africa. (2017). Poverty trends in South Africa: An examination of absolute poverty between 2006 and 2015. Statistics South Africa, August. Retrieved from http://www.statssa.gov.za/?p=10341

Statistics South Africa. (2016). Community survey 2016. Retrieved from http://cs2016.statssa.gov.za/wpcontent/uploads/2016/07/NT-30-06-2016-RELEASE-for-CS-2016-_Statistical-releas_1-July2016.pdf

Trebilcock, M. \& Rosenstock, M. (2015). Infrastructure public-private partnerships in the developing world: Lessons from recent experience. Journal of Development Studies, 51(4), 335-354.

Turton, A. (2016). South Africa and the drought that exposed a young democracy. Journal of Water Policy, 18, 210-227.

Van den Brink, R. (2011.) Accountability in public services in South Africa. The World Bank. Retrieved from http://siteresources.worldbank.org/INTSOUTHAFRICA/Resources/Accountability_in_Public_ Services_in_Africa.pdf

Venkatachalam, L. (2015). Informal water markets and willingness to pay for water: A case study of the urban poor in Chennai City, India. International Journal of Water Resources Development, 31(1), 134-145.

Water directory. (2017). Water Research Commission. Retrieved from http://www.wrc.org.za/Pages/Resources_waterdirectory.aspx

Welch, C, 2018. How Cape Town is coping with its worst drought on record. National Geographic, 5 March. Retrieved from https://news.nationalgeographic.com/2018/02/cape-town-running-out-of-waterdrought-taps-shutoff-other-cities $\angle$

WHO (World Health Organization). (2011). Guidelines for drinking-water quality. Fourth Edition. Retrieved from http://apps.who.int/iris/bitstream/10665/44584/1/9789241548151_eng.pdf

Zolnikov, T.R. \& Salafia, E.B. (2016). Improved relationships in Eastern Kenya from water interventions and access to water. Journal of Health Psychology, 35(3), 273-280. 